\title{
The eyewitness suggestibility effect and memory for source
}

\author{
D. STEPHEN LINDSAY \\ Williams College, Williamstown, Massachusetts \\ and \\ MARCIA K. JOHNSON \\ Princeton University, Princeton, New Jersey
}

\begin{abstract}
We examined the possibility that eyewitness suggestibility reflects failures of the processes by which people normally discriminate between memories derived from different sources. To test this hypothesis, misled and control subjects were tested either with a yes/no recognition test or with a "source monitoring" test designed to orient subjects to attend to information about the sources of their memories. The results demonstrate that suggestibility effects obtained with a recognition test can be eliminated by orienting subjects toward thinking about the sources of their memories while taking the test. Our findings indicate that although misled subjects are capable of identifying the source of their memories of misleading suggestions, they nonetheless sometimes misidentify them as memories derived from the original event. The extent to which such errors reflect genuine memory confusions (produced, for example, by lax judgment criteria) or conscious misattributions (perhaps due to demand characteristics) remains to be specified.
\end{abstract}

E. F. Loftus and her colleagues (e.g., E. F. Loftus, 1979; E. F. Loftus, Miller, \& Burns, 1978; Wells \& E. F. Loftus, 1984) have demonstrated that subjects are susceptible to misleading suggestions about recently witnessed events. In a typical study of eyewitness suggestibility, subjects are shown a series of slides depicting an event and then some subjects are given verbal misleading suggestions concerning details in the original event. When tested, misled subjects often claim to have seen things that actually were only suggested.

E. F. Loftus (e.g., 1979, 1981; E. F. Loftus \& G. R. Loftus, 1980) has argued that the memory of the misleading suggestion "overwrites" and replaces the memory of the event as it was witnessed. Briefly, Loftus proposed that information about an event is stored in memory as an integrated whole. When new information about a particular event is received, it is integrated into the previously formed memory. If the new information is incon-

This research was supported in part by National Science Foundation Grant BNS8510633 to Marcia K. Johnson. We wish to express our gratitude to the teachers who so generously shared their classes with us (Fred Cerequas, David Cross, Catherine Hanson, William Kennedy, and Dale Miller) and to their students. Thanks are also due Mary Ann Opperman, who coordinated our research in high schools; John Fleming, who provided advice on statistical programs; and Marisa Carrasco, who provided an invaluable link to Princeton's computer system after both authors left town. We would like to thank Veronica Anderson, Joe Dougherty, Jeanne Kinney, and John Knight, who helped conduct a pilot study of Experiment 1 as part of a laboratory exercise. Robert Buckhout, James I. Chumbley, Ronald P. Fisher, Saul Kassin, Colleen Kelley, and an anonymous reviewer provided insightful comments on earlier drafts. Requests for reprints should be sent to Steve Lindsay, Department of Psychology, Bronfman Science Center, Williams College, Williamstown, MA 01267 . sistent with some aspect of the memory of the visual scene, the earlier memory may be "updated" in a way that alters the representation of the original information.

A number of recent articles have questioned the overwriting/updating theory. McCloskey and Zaragoza (1985a, 1985b) criticized E. F. Loftus's position on both methodological and a priori grounds, and presented compelling evidence against the overwriting hypothesis. Several investigators (Alba, 1984; Bekerian \& Bowers, 1983; Christiaansen \& Ochalek, 1983; Morton, Hammersley, \& Bekerian, 1985; Pirolli \& Mitterer, 1984; Shaughnessy \& Mand, 1982; Wagenaar, 1987) have demonstrated the coexistence of memory for the original information and memory for the misleading suggestion under conditions that produce suggestibility effects. Thus it is clear that memory of the original detail is not obliterated by misleading suggestions. (See McCloskey \& Zaragoza, 1985a, for critiques of some of these studies.)

Given that new information does not destroy memory for old information, why do misled subjects claim that the suggested information was present in the original visual depiction of the event? There are several potential explanations. Below, we briefly summarize the two major approaches offered to date, then consider a third possibility.

\section{Accessibility}

Several investigators (e.g., Bekerian \& Bowers, 1983; Christiaansen \& Ochalek, 1983; Pirolli \& Mitterer, 1984) have argued that misled subjects' ability to remember the original information is impaired indirectly because the misleading suggestion is retrieved from memory more quickly and easily than the original information. The mis- 
leading suggestion is more recent and may be more salient than the original information. Therefore, the memory of the misleading suggestion is likely to be more accessible than the memory of the original detail, and thus may interfere with the retrieval of the memory of the original information (an idea similar to McGeoch's, 1942, notion of response competition).

\section{Nonretention}

McCloskey and Zaragoza (1985a) pointed out that suggestibility effects need not entail any effect of misleading suggestions on subjects' ability to remember the original information. Their argument is as follows: (1) Some subjects in both the misled and control conditions fail to notice or retain the critical detail in the original visual event (that is to say, due to pure happenstance, some subjects never form a memory of the critical detail in the first place, or spontaneously forget it before the misleading information is presented). (2) When control subjects spontaneously fail to notice or retain the critical detail in the original event, they must guess on the critical test pair (and hence will select the correct alternative $50 \%$ of the time). (3) When misled subjects spontaneously fail to notice or retain the critical detail in the original event, they need not merely guess on the test; instead, if they noticed and retained the misleading suggestion, they may use their memory of it to guide their choice on the critical test pair (and hence will select the incorrect alternative). It follows that subjects in the misled condition will choose the incorrect alternative on the critical test pair more often than control subjects, not because the misleading suggestion affected the memory of the original information, but because some subjects never had the original information in memory or spontaneously forgot it before the misleading suggestion was given.

\section{Source Monitoring}

We suspect that both accessibility and nonretention play roles in producing suggestibility effects. Both accounts, however, leave open an important question: Why do misled subjects claim that they saw the suggested detail in the original depiction of the event? There are two major alternative explanations. It may be that misled subjects know that the memory of the suggested detail was derived from the verbal message they received after witnessing the event, but nonetheless use that memory to guide their choice on the test. As McCloskey and Zaragoza (1985a) pointed out, there are several reasons why subjects might behave this way (demand characteristics, trust in the veridicality of the postevent information, etc.). On the other hand, it may be that misled subjects genuinely believe that they saw the suggested item in the original depiction of the event. That is, misled subjects may misidentify the source of the memory of the suggested detail, and in fact believe that it is a memory derived from the original visual depiction of the event.

Why would subjects believe that a memory derived from one source had been derived from another? John- son and her co-workers (e.g., Johnson, 1988; Johnson \& Raye, 1981) have demonstrated that people sometimes mistake memories of imagined events for memories of actual events (and vice versa), and that the likelihood of such "reality monitoring" errors varies with the degree of similarity between memories of imagined and actual events. For example, good imagers are more likely than poor imagers to confuse memories of imagining seeing a picture and memories of actually seeing a picture, presumably because memories of seeing and of imagining are more similar (and hence more confusable) among people with good imagery than among people with poor imagery (Johnson, Raye, Wang, \& Taylor, 1979; see also Johnson, Foley, \& Leach, 1988).

In related work, Lindsay (1987; Lindsay \& Johnson, 1989b) found that people sometimes believe that a memory derived from one external source was derived from another external source (see also Fisher \& Cuervo, 1983; Geiselman \& Crawley, 1983; Hashtroudi, Johnson, \& Chrosniak, 1989). Anecdotal evidence suggests that such "source monitoring" errors are among the most common of memory failures. People frequently experience difficulty in remembering the sources of memories that are otherwise clear (e.g., one might remember hearing a particular statement but be unable to recall who made it). Moreover, people sometimes make erroneous source attributions (e.g., thinking that Liz said something that was actually said by Kathy). Lindsay's (1987; Lindsay \& Johnson, 1989b) findings indicate that the likelihood of such source-monitoring errors varies with the degree of similarity between potential sources: in a series of experiments, source-monitoring errors were found to be more frequent when potential memory sources were similar to one another in terms of their perceptual properties, modality of presentation, semantic content, or cognitive operations (orienting task).

The procedures used in studies of eyewitness suggestibility create ideal conditions for source-monitoring errors. Both the original information and the postevent information concern the same topic, and both are typically presented close together in time, in the same environment, by the same experimenter, and so forth. These similarities may make it difficult for subjects to later discriminate between memories derived from the postevent information and memories derived from the original depiction of the event.

Our hypothesis was that confusions of memories derived from different sources may contribute to the eyewitness suggestibility effect. This source-monitoring hypothesis differs from Loftus's overwriting account in that, according to our hypothesis, misleading suggestions need not have any effect on the memory representation of the original event. Our view differs from McCloskey and Zaragoza's (1985a, 1985b) nonretention explanation in that, according to our hypothesis, source confusions may occur whether or not memory for the original detail exists. (McCloskey and Zaragoza noted the possibility that suggestibility effects may involve genuine memory con- 
fusions, but concluded that current evidence is best explained in terms of spontaneous nonretention of critical details from the original event and demand characteristics.) Finally, the source-monitoring hypothesis differs from accessibility accounts in that it attempts to explain why subjects might believe that a memory derived from one source (the postevent information) was derived from another source (the original event), whereas accessibility accounts have attempted to explain only why misled subjects might have more difficulty in accessing the memory of the original detail than do control subjects.

As others (e.g., Bekerian \& Bowers, 1983; McCloskey \& Zaragoza, 1985a; Shaughnessy \& Mand, 1982; Tversky \& Tuchin, 1989) have noted, concepts derived from interference theory are relevant to suggestibility. Different approaches to suggestibility have emphasized different interference mechanisms. Updating (e.g., E. F. Loftus \& G. R. Loftus, 1980), accessibility (e.g., Bekerian \& Bowers, 1983), and source monitoring have parallels in earlier accounts of forgetting framed in terms of unlearning (Melton \& Irwin, 1940), response competition (or the independence hypothesis; McGeoch, 1942), and list differentiation (Abra, 1972; Underwood, 1945; Winograd, 1968), respectively (see, e.g., Crowder, 1976). The newer theoretical terms grow out of current conceptions of memory representations for complex events, but the question of the relative contributions of various potential mechanisms of forgetting has long been a difficult and fundamental issue.

According to the source-monitoring hypothesis, suggestibility effects occur at test when misled subjects erroneously identify memories derived from the misleading information as memories derived from the scene itself. If it is indeed the case that subjects are making judgments about the sources of memories when they are tested, then their judgments should be affected by the decision-making processes and criteria they adopt on the test (Hasher \& Griffin, 1978; Johnson, 1988; Raye, Johnson, \& Taylor, 1980). According to the source-monitoring hypothesis, the criteria subjects use to attribute a memory to a particular source may vary with a number of factors (for example, the purpose of the remembering, biases, and plausibility) (Johnson, 1988). By criteria, we mean the characteristics of a memory that the person remembering takes as evidence that it came from a particular source. Under some conditions it might be sufficient that an item is familiar and fits with other details derived from that source, and under other circumstances further information, such as a perceptually detailed recollection, might be required.

Recognition tests like those typically used in studies of eyewitness suggestibility may actually induce subjects to make source-monitoring errors on the critical items. In the standard procedure, subjects receive a series of recognition trials consisting of items from the original event and new distractor items (either in the form of forcedchoice pairs or individual yes/no items). The critical test items, in which the suggested objects appear, are embedded among these filler items. Because most of the test items require subjects to discriminate between objects presented in the visual event and completely new distractors, subjects may adopt a familiarity criterion (Atkinson \& Juola, 1973; Jacoby \& Dallas, 1981) early on in the test, and stop attending to potentially useful information about the sources of their memories (e.g., the amount and nature of perceptual detail). When a suggested item is encountered, subjects may recognize it as something presented during the experimental session and, because they are using a familiarity criterion, indicate that they remember seeing that item in the original event. On a forcedchoice test, the suggested item in a test pair may seem more familiar than the original item for a number of reasons (recency, salience, etc.). Thus, standard testing procedures with both yes/no and forced-choice recognition tests may lead subjects to base judgments on familiarity and hence to ignore memory information about the source of an item's familiarity. It may be that subjects would make fewer errors if they were oriented toward source-monitoring judgments (e.g., Lindsay, 1987; Raye \& Johnson, 1980) rather than familiarity judgments (e.g., E. F. Loftus, 1979).

To test this hypothesis, in the present experiments we tested misled and control subjects with one of two tests. As in the standard procedure, all subjects first viewed pictorial target information and then received verbal postevent information (with or without misleading suggestions). Later, half of the subjects were given a yes/no recognition test and the remaining subjects were given a source-monitoring test. The yes/no recognition test required the subjects to indicate which items they had seen in the picture and which they had not. The sourcemonitoring test required the subjects to indicate the source of the memory of each item they recognized as old. We predicted that subjects given the source-monitoring test would show less suggestibility than subjects given the yes/no recognition test, because source-monitoring instructions should prompt the subjects to use more specific information for evaluating memories at the time of the test.

\section{EXPERIMENT 1}

\section{Method}

The subjects were tested in groups, and each group included subjects in all four conditions. In the first phase of the experiment, all subjects studied the same slide, which depicted a complex office scene. In the second phase of the experiment, all subjects read a detailed narrative description of the scene. For half of the subjects (those in the control conditions), the narrative included only accurate information. For the remaining subjects (those in the misled conditions), the narrative also mentioned eight objects that fit with the general theme of the scene but were not actually present in the picture. In the third phase of the experiment, the subjects were tested with either a yes/no recognition test or a source-monitoring test. Both tests included iterns presented only in the picture, items presented in both the picture and the text, items presented only in the misleading text, and new distractor items. 
Subjects. A total of 117 subjects of both sexes participated in the experiment: 28 were undergraduate students at Princeton University, and 89 were undergraduate students at the State University of New York, Stony Brook. The experiment was conducted as an optional demonstration experiment in one class at each of these institutions. In each class, those students who volunteered to participate were randomly assigned to the four conditions, with approximately equal numbers of subjects in each condition in each class. The data from 9 subjects were randomly selected and discarded to obtain an equal number of subjects (27) in each of the four conditions. Thus, the data from 108 subjects were included in the analyses.

Materials. A color slide was made of a photograph published in Psychology Today (June 1985, pp. 56-57). The slide depicted a cluttered office scene, with four people in various poses amid a variety of office paraphernalia. A list of 16 objects pictured in this scene (coffee cup, pinstripe suit, pencil holder, etc.) was generated, and the items on this list were randomly assigned to one of two sets: picture-and-text and picture-only. The 8 items in the picture-and-text set were mentioned in both the misleading and control texts, whereas those in the picture-only set were not mentioned in either text. A second list of 16 objects was also generated. This list consisted of objects that fit with the general theme of the scene but were not actually present in it (coffeepot, coatrack, typewriter, etc.). The items in this list were randomly assigned to two sets: misleading-text-only and new. The misleading-text-only items were mentioned in the misleading text, whereas those in the new set were reserved for use as distractor items on the test.

Two texts were written, each approximately 400 words long. The control text was constructed by interleaving, with connecting narrative, the items from the picture-and-text set with other objects that were in the scene but had not been assigned to a set. Thus the control text was a detailed and accurate description of the scene. The misleading text was constructed by inserting misleadingtext-only items at appropriate points in the control text (see Appendix).

Both the yes/no recognition test and the source-monitoring test consisted of 32 items: 8 picture-only, 8 picture-and-text, 8 misleadingtext-only, and $8 \mathrm{new}$. The order of items was randomized, with the constraint that no more than 2 items from a given set occur in succession.

Typed test instructions were presented on a separate page of the booklet given to the subjects, preceding the test itself. The instructions for the yes/no recognition test read as follows:

For each of the items on the following pages, please indicate whether or not the item was present in the picture by checking the box in the appropriate column. If the item was present in the picture, check the box under the word "Yes." If not, check the box under the word "No."

The yes/no response sheets consisted of a list of the 32 test items and a response column with the heading "In Picture?" and alternatives "Yes" and "No."

The instructions for the source-monitoring test read as follows:

For each of the items on the following pages, please indicate whether the item was (a) present only in the picture, (b) present only in the text, (c) present in both the picture and the text, or (d) present in neither the picture nor the text. Indicate your answer by checking the appropriate column.

The response sheets consisted of a list of the 32 test items and a response column with the heading "Source?" and alternatives "Pict," "Text," "Both," and "None."

Each subject was given a booklet consisting of an opaque cover page, the misleading or control narrative, the test instructions, and the test response sheet.

Procedure. The subjects were told that this was an experiment concerning memory for pictorial and verbal information. They were informed that they were to study a slide and then read a narrative description of the scene depicted in that slide, and that they would later be given a memory test.

The subjects were warned that the slide would be presented for only a brief time, and they were instructed to study it closely. The slide was then presented for $20 \mathrm{sec}$. After the slide was removed, the booklets were distributed and instructions for reading the text were given. Approximately 2 to $3 \mathrm{~min}$ elapsed between removal of the slide and the signal to begin reading the narrative. After all subjects had read the narrative, they were asked to read the test instructions carefully. When all subjects indicated that they had read and understood the test instructions, they were asked to begin the test.

\section{Results}

On the source-monitoring test, an item was scored as having been attributed to the picture if the subject responded either "Picture" or "Both" to that item. On the yes/no recognition test, an item was scored as having been attributed to the picture if the subject responded "Yes" to that item. Thus the chance probability of attributing an item to the picture was the same (.5) for both test conditions. The data for each type of item (pictureonly, misleading-text-only, picture-and-text, and new) were analyzed with separate two-way ANOVAs (misleading vs. control narrative $\times$ yes/no vs. source-monitoring test). The .01 level of confidence was used for all statistical tests.

The mean number of test items of each type (misleadingtext-only, picture-only, picture-and-text, and new) attributed to the picture are presented in Table 1. As predicted, among subjects given the yes/no recognition test, those who read the misleading narrative claimed that they had seen significantly more of the suggested objects in the picture $(M=5.52)$ than did those who read the control narrative $(M=2.67)\left[F(1,52)=33.05, M S_{e}=\right.$ 3.81]. Among subjects given the source-monitoring test, on the other hand, no such suggestibility effect was obtained; that is, among source-monitoring subjects, those who read the misleading narrative did not claim that they had seen significantly more of the suggested items in the picture $(M=2.56)$ than did those who read the control text $(M=2.41)(F<1)$. This text $\times$ test interaction is significant $\left[F(1,104)=13.30, M S_{\mathrm{e}}=3.71\right]$.

The effect of the source-monitoring test was not restricted to the misleading-text-only items. Subjects given the source-monitoring test tended to attribute fewer items

Table 1

Experiment 1: Mean Number of Items of Each Type Attributed to the Picture

\begin{tabular}{lcccc} 
& \multicolumn{4}{c}{ Item Type } \\
\cline { 2 - 5 } Condition & $\begin{array}{c}\text { Misleading } \\
\text { Text Only }\end{array}$ & $\begin{array}{c}\text { Picture } \\
\text { Only }\end{array}$ & Picture and Text & New \\
\hline Control/YN & 2.67 & 5.96 & 6.56 & 2.22 \\
Misled/YN & 5.52 & 5.26 & 6.48 & 1.37 \\
Control/SM & 2.41 & 5.37 & 4.04 & 1.78 \\
Misled/SM & 2.56 & 4.93 & 4.37 & 1.26 \\
\hline
\end{tabular}

Note-There were eight items of each type. YN = yes/no test; $S M=$ source-monitoring test. 
of all four types to the picture than did subjects given the yes/no test, but the effect was significant only on the misleading-text-only and picture-and-text items $[F(1,104)$ $=18.89, M S_{\mathrm{e}}=3.71$, and $F(1,104)=60.03, M S_{\mathrm{e}}=$ 2.41 , respectively] (see Table 1 ). ${ }^{1}$

Although the source-monitoring test reduced the frequency with which subjects attributed items to the picture, it did not increase the frequency with which they rejected old items as new (i.e., it did not increase miss rates). On the contrary, as is clear in Table 2 , subjects given the source-monitoring test tended to classify old items as new less often than did subjects tested with the yes/no test. Once again, the effect is significant only for the misleading-text-only and picture-and-text items $\left[F(1,104)=4.76, M S_{\mathrm{e}}=3.27\right.$, and $F(1,104)=4.63$, $M S_{\mathrm{e}}=1.80$, respectively].

Table 3 presents the mean number of items of each type attributed to the text by subjects given the sourcemonitoring test. Whereas yes/no subjects tended to respond "Yes" to old items of all types (i.e., pictureonly, picture-and-text, and misleading-text-only), sourcemonitoring subjects often attributed to the text those items that were mentioned in the text (i.e., picture-and-text and, for subjects in the misled condition, misleading-text-only).

\section{Discussion}

In this experiment, misled subjects given the yes/no recognition test often attributed suggested items to the picture, whereas misled subjects given the source-monitoring test attributed those items to their actual source-the text. Although we expected to reduce suggestibility with the source-monitoring test, we were surprised that it eliminated the effect altogether. Source-monitoring subjects did not demonstrate perfect memory for source, but false attributions of misleading-text-only items to the picture were no more common among those in the misled condition than among those in the control condition.

Table 2

Experiment 1: Mean Number of Items of Each Type Classified as New

\begin{tabular}{lcccc}
\multicolumn{5}{c}{ of Each Type Classified as New } \\
\cline { 2 - 5 } & \multicolumn{4}{c}{ Item Type } \\
\cline { 2 - 5 } Condition & $\begin{array}{c}\text { Misleading } \\
\text { Text Only }\end{array}$ & $\begin{array}{c}\text { Picture } \\
\text { Only }\end{array}$ & Picture and Text & New \\
\hline Control/YN & 5.33 & 2.00 & 1.44 & 5.78 \\
Misled/YN & 2.48 & 2.67 & 1.52 & 6.33 \\
Control/SM & 4.78 & 1.89 & 0.89 & 5.63 \\
Misled/SM & 1.52 & 2.52 & 0.96 & 6.30 \\
\hline
\end{tabular}

Note-There were eight items of each type. YN = yes/no test; $S M=$ source-monitoring test.

Table 3

Experiment 1: Mean Number of Items of Each Type Attributed to the Text by Subjects Given the Source-Monitoring Test

\begin{tabular}{|c|c|c|c|c|}
\hline \multirow[b]{2}{*}{ Condition } & \multicolumn{4}{|c|}{ Item Type } \\
\hline & $\begin{array}{l}\text { Misleading } \\
\text { Text Only }\end{array}$ & $\begin{array}{c}\text { Picture } \\
\text { Only }\end{array}$ & Picture and Text & New \\
\hline Control & 0.82 & 0.70 & 3.07 & 0.52 \\
\hline Misled & 3.93 & 0.52 & 2.67 & 0.44 \\
\hline
\end{tabular}

Note-There were eight items of each type
One potential explanation for the failure to obtain a significant suggestibility effect among subjects given the source-monitoring test is that the test instructions may have functioned as a warning about the existence of textonly items. That is, the instruction to indicate which items had been "present only in the text" may have alerted subjects given the source-monitoring test to the fact that some items mentioned in the text had not appeared in the picture (cf. Christiaansen \& Ochalek, 1983).

Another factor that may have contributed to the difference in performance between source-monitoring and yes/no subjects was the wording of the instructions for the yes/no recognition test. The subjects were to respond "Yes" to items that had been "present in the picture." With these instructions, subjects who assumed the text to be veridical might well respond "Yes" to items they knew they had not seen in the picture but that they remembered reading about. Thus subjects who responded "Yes" to a suggested item were not necessarily claiming that they had seen that item.

\section{EXPERIMENT 2}

The primary purpose of Experiment 2 was to replicate Experiment 1 while reducing the likelihood that the instructions for the source-monitoring test would warn subjects about the misleading suggestions in the text. To this end, the source-monitoring test instructions were rewritten. To further increase the likelihood that misled subjects tested with the source-monitoring test would make source-monitoring errors (i.e., would claim to have seen objects actually only suggested in the text), the subjects were not warned in advance that their memories would be tested; instead, a cover story was presented in which the experiment was described as a study of the way people interpret complex visual and verbal scenes. Finally, the instructions for the yes/no recognition test were reworded in such a way as to clarify the interpretation of "Yes" responses.

\section{Method}

Subjects. A total of 136 subjects of both sexes participated in the experiment: 56 were juniors and seniors at a New Jersey high school, and 80 were undergraduates at Princeton University. The experiment was conducted as an optional demonstration experiment. The high-school students were tested in five classroom groups, and the undergraduates in a single lecture-hall group. Within each group, those students who wished to participate were randomly assigned to the four conditions, with approximately equal numbers of subjects per condition in each group. Four randomly selected subjects were dropped in order to obtain an equal number of subjects (33) in each condition. Thus, the data from 132 subjects were included in the analyses.

Materials. The photographic slide, texts, and test items were the same as those used in Experiment 1. The only difference was in the wording of the test instructions. In the present experiment, subjects given the yes/no test were to respond "Yes" to each item they remembered seeing in the picture and "No" to items they did not remember seeing in the picture. The source-monitoring test instructions suggested that people tend to remember different kinds of information from verbal and pictorial presentations. These instruc- 
tions implied that all of the test items had been presented in both the picture and the text, and asked the subjects to indicate in which of the two they remembered noticing each item. The subjects were to respond "Picture" if they remembered noticing the item only in the picture, "Text" if they remembered the item only in the text, "Both" if they remembered the item in both the picture and the text, and "Neither" if they did not remember the item at all.

Procedure. The experiment was introduced as a study of the way people interpret complex scenes. The subjects were told that they would be shown a slide of a scene and were then to read a narrative description of that scene, and that after each presentation they would be asked to write a brief interpretation of the nature of the scene. The subjects' written interpretations were used only to support the cover story about the nature of the experiment. The slide was presented for $20 \mathrm{sec}$, after which the booklets were distributed and the subjects were given $2 \mathrm{~min}$ to write their interpretations of the pictorial scene. Immediately thereafter, the subjects were instructed to read the narrative description of the scene. When all subjects had read the narrative, they were again given $2 \mathrm{~min}$ to write a brief interpretation of the scene. They were then told of the surprise memory test and asked to read the test instructions. When all subjects indicated that they had read and understood the instructions, they were asked to begin the test.

\section{Results}

The data were scored and analyzed as in Experiment 1. The mean number of test items of each type (misleadingtext-only, picture-only, picture-and-text, and new) attributed to the picture are presented in Table 4. As in Experiment 1 , a significant suggestibility effect was obtained among subjects given the yes/no recognition test but not among subjects given the source-monitoring test. Among the yes/no subjects, those who read the misleading narrative claimed they had seen significantly more of the suggested items $(M=3.91)$ than did those who read the control narrative $(M=2.30)\left[F(1,64)=13.11, M S_{c}=\right.$ 2.54]. Among the source-monitoring subjects, those who read the misleading narrative did not claim they had seen more of the suggested items $(M=1.39)$ than did those who read the control narrative $(M=1.33)(F<1)$. This text $\times$ test interaction is significant $[F(1,128)=8.06$, $\left.M S_{\mathrm{e}}=2.54\right]$.

As in Experiment 1, the effect of the source-monitoring test was not restricted to the misleading-text-only items. Source-monitoring subjects attributed fewer items of all four types to the picture [in this case, the effect is signifi-

Table 4

Experiment 2: Mean Number of Items of Each Type Attributed to the Picture

\begin{tabular}{lcccc}
\hline & \multicolumn{4}{c}{ Item Type } \\
\cline { 2 - 5 } Condition & $\begin{array}{c}\text { Misleading } \\
\text { Text Only }\end{array}$ & $\begin{array}{c}\text { Picture } \\
\text { Only }\end{array}$ & Picture and Text & New \\
\hline Control/YN & 2.30 & 5.46 & 5.06 & 1.76 \\
Misled/YN & 3.91 & 5.73 & 5.55 & 1.70 \\
Control/SM & 1.36 & 4.52 & 2.58 & 1.03 \\
Misled/SM & 1.39 & 4.00 & 2.42 & 0.97 \\
\hline
\end{tabular}

Note-There were eight items of each type. YN = yes/no test; SM = source-monitoring test.
Table 5

Experiment 2: Mean Number of Items of Each Type Classified as New

\begin{tabular}{lcccc}
\hline & \multicolumn{4}{c}{ Item Type } \\
\cline { 2 - 5 } Condition & $\begin{array}{c}\text { Misleading } \\
\text { Text Only }\end{array}$ & $\begin{array}{c}\text { Picture } \\
\text { Only }\end{array}$ & Picture and Text & New \\
\hline Control/YN & 5.70 & 2.55 & 2.94 & 6.24 \\
Misled/YN & 4.09 & 2.24 & 2.46 & 6.30 \\
Control/SM & 5.49 & 2.76 & 0.94 & 6.33 \\
Misled/SM & 3.42 & 3.00 & 2.06 & 6.58 \\
\hline
\end{tabular}

Note-There were eight items of each type. YN = yes/no test; $S M=$ source-monitoring test.

Table 6

Experiment 2: Mean Number of Items of Each Type Attributed to the Text by Subjects Given the Source-Monitoring Test

\begin{tabular}{lcccc} 
& \multicolumn{4}{c}{ Item Type } \\
\cline { 2 - 5 } Condition & Misleading & Picture & & \\
Text Only & Only & Picture and Text & New \\
\hline Control & 1.10 & 0.73 & 4.42 & 0.54 \\
Misled & 3.18 & 1.00 & 3.48 & 0.42 \\
\hline
\end{tabular}

Note-There were eight items of each type.

cant for all four item types; all $F \mathrm{~s}(1,128)>8.83$ ]. Once again, although the source-monitoring test reduced the frequency with which subjects attributed items to the picture, it did not increase the miss rates. As is clear in Table 5, source-monitoring subjects classified old items as new slightly less often than did yes/no subjects [this effect is significant only for the picture-and-text items; $F(1,128)=19.53, M S_{\mathrm{e}}=2.42 \mathrm{]}$.

Table 6 presents the mean number of items of each type attributed to the text by subjects given the sourcemonitoring test. In contrast to the yes/no subjects, who often responded "Yes" to old items whether they had been presented in the picture or in the text alone, sourcemonitoring subjects often attributed to the text those items that had been mentioned in the text (i.e., picture-and-text items and, for subjects in the misled condition, misleadingtext-only items).

\section{Discussion}

A significant suggestibility effect was obtained among subjects tested with the yes/no recognition test, but not among subjects tested with the source-monitoring test. Misled subjects given the yes/no test often claimed that they had seen suggested items in the picture, whereas those tested with the source-monitoring test attributed those items to their actual source-the text.

\section{GENERAL DISCUSSION}

The results of the experiments reported here demonstrate that orienting subjects toward making sourcemonitoring judgments can eliminate the eyewitness suggestibility effect that is obtained when the same procedures and materials are used but subjects are tested with 
a recognition test. Clearly, the nature of the test instructions (yes/no vs. source-monitoring) has a marked effect on the magnitude of the suggestibility effect. Furthermore, the suggestibility effect observed among subjects tested with the yes/no recognition test in Experiment 2 was about half that observed in Experiment 1. A key difference between these two groups was in the wording of the instructions for the recognition test: In Experiment 1, the subjects were instructed to respond "Yes" to each item that had been "present in the picture," whereas in Experiment 2 the subjects were to respond "Yes" only if they remembered seeing the item in the picture. Although it is risky to compare means across studies, this contrast, like that between recognition and source-monitoring instructions, supports our contention that changes in test instructions can affect the discriminations subjects attempt to make.

In Experiment 1, subjects given the yes/no test more often claimed that they had seen picture-and-text items than that they had seen picture-only items, whereas subjects given the source-monitoring test more often claimed that they had seen picture-only items than that they had seen picture-and-text items [for the interaction, $F(1,104)$ $\left.=20.76, M S_{\mathrm{e}}=2.66\right]$. This interaction supports our hypothesis that yes/no subjects base their judgments on familiarity (and hence respond "Yes" most often to items presented in both sources), whereas source-monitoring subjects base their responses on source-relevant memory information (and hence often attribute picture-and-text items to the text). A similar interaction between item type (picture-only vs. picture-and-text) and test (yes/no vs. source-monitoring) was obtained in Experiment 2 $\left[F(1,128)=19.22, M S_{\mathrm{e}}=2.63\right]$. In Experiment 2, subjects given the yes/no test attributed approximately equal numbers of picture-only and picture-and-text items to the picture, whereas subjects given the source-monitoring test more often attributed picture-only items than picture-andtext items to the picture. ${ }^{2}$

Both misled and control subjects attributed fewer items that really were in the picture to the picture if they were tested with the source-monitoring test than if they were tested with the yes/no recognition test. These differences were not due to relatively high levels of "new" responses (i.e., misses) among subjects given the source-monitoring test; instead, they reflect the fact that source-monitoring subjects attributed some of these items to the text. This pattern of results suggests that the source-monitoring test induced subjects to employ relatively exacting criteria (e.g., memory of perceptual detail) when making memory decisions. By requiring memory of pictorial detail, for example, before attributing a memory of an item to the picture, subjects given the source-monitoring test were able to "edit out" memories of the misleading suggestions; the same stringent criteria, however, caused subjects to misattribute to the text some memories actually derived from the picture.

Previous research (Christiaansen \& Ochalek, 1983) has demonstrated that warning subjects about the existence of misleading information in a postevent narrative can reduce or eliminate suggestibility, even when the warning is given after the narrative is read. These findings have been used to argue against the overwriting hypothesis and in favor of the accessibility hypothesis, but McCloskey and Zaragoza (1985a) argued that they do not provide strong evidence about either position. The findings do demonstrate, however, that subjects are capable of identifying the source of memories derived from the text; that is, a warning about the veridicality of the text, like sourcemonitoring instructions, may induce subjects to monitor the sources of their memories relatively closely, and consequently may allow them to edit out memories derived only from the text.

There were several procedural differences between our experiment and others on suggestibility. Our original information consisted of a single slide, rather than a sequence of slides. Most previous studies used only one to four misleading suggestions, whereas our misleading narrative included eight such suggestions. In our study the misleading information suggested the existence of objects not actually present in the scene (e.g., a coffeepot), whereas often the misleading information directly contradicts particular details in the original information (e.g., subjects view a yield sign and a stop sign is suggested; but see E. F. Loftus, 1975, 1981, for procedures like ours in this respect). Also, we used a yes/no recognition test, but most previous studies used a forced-choice test. At a more general level, however, our procedure was similar to the standard procedure: visually presented information was followed by misleading verbal information, and memory for the original information was tested. It is evidence of the robustness of the phenomenon that, despite the differences, our results were essentially the same as those obtained with the standard procedure: When tested with a recognition test, misled subjects often claimed that they had seen things that had only been suggested in the text.

The present experiments demonstrate that suggestibility is affected by the decision-making processes and criteria subjects use at test. Another interesting implication of the source-monitoring hypothesis is that suggestibility should occur even when the misleading suggestions are given before the visual information is presented. Consistent with this idea, we (Lindsay \& Johnson, 1989a) obtained a suggestibility effect in a procedure in which subjects first read a narrative description of a scene (with or without misleading suggestions) and then viewed the scene to which that narrative referred. Although these results are not incompatible with the hypothesis that memories from different sources may be integrated, they do contradict the more specific hypothesis that suggestibility consists of newer information updating older memories.

The notion that the sources of memories are identified via decision-making processes performed during remembering - and the claim that these processes sometimes result in erroneous attributions-has implications for a number of issues in forensic memory research. Con- 
sider, as one example, Brown, Deffenbacher, and Sturgill's (1977) finding that subjects who studied a set of mug shots after viewing a staged crime often erred on a later lineup test by selecting a person whose face they had seen in the mug shots, rather than the actual "criminal." As Brown et al. (1977, p. 317) noted, "face recognition is much better than recall of circumstances of encounter, raising the possibility that ... witnesses might base their indictments on face recognition alone." What Brown et al. referred to as "recall of circumstances of encounter" is analogous to our concept of memory for source; that is, subjects in these mug shot studies sometimes mistook a memory derived from the mug shots for a memory derived from the staged crime. An understanding of the processes by which people identify the sources of their memories would provide a basis for predictions concerning the likelihood of such errors.

An important question of interest for understanding the nature of the eyewitness suggestibility effect is whether misled subjects who respond "Yes" to suggested items really believe that they saw those objects in the scene itself. Our results indicate that misled subjects are capable of identifying the actual source of their memories of the misleading suggestions. (Zaragoza \& Koshmider, 1989, found similar results using a slightly different sourcemonitoring test.) These findings can be taken as further evidence against E. F. Loftus's updating hypothesis. One might also argue, on the basis of these findings, that the subjects tested with the recognition test in the present experiments, who did show a substantial suggestibility effect, were aware that their memories of the suggested items were derived from the postevent information rather than from the scene itself. Thus one might conclude that eyewitness suggestibility effects reflect nothing other than demand characteristics and do not involve genuine memory-source confusions.

Given the available evidence, the demand-characteristics interpretation (e.g., McCloskey \& Zaragoza, 1985a) is reasonable. It suffers, however, from two major limitations that make us cautious about subscribing to it as the sole explanation of eyewitness suggestibility effects. First, although our data demonstrate that our subjects were capable of identifying the sources of their memories correctly when directed to do so, this does not necessarily mean that the subjects given the yes/no test did so spontaneously. What information from memory is activated, and how the activated information is used, depends on test conditions. Furthermore, what is sufficient evidence for believing something under some conditions may be insufficient under others (Johnson, 1988). As we have argued, recognition tests may lead subjects to neglect sourcerelevant memory information. Thus it is possible that subjects given the yes/no test genuinely mistook memories derived from the narrative for memories derived from the picture itself, given the source-monitoring criteria they were using.
A second limitation of demand characteristics as a general explanation of eyewitness suggestibility effects is that we know from other studies (and from everyday experience) that people do sometimes misidentify the sources of their memories. For example, as mentioned previously, Lindsay (1987) found that people sometimes misattributed memories derived from one source to another source, even when they were instructed explicitly to remember the sources of their memories, and under conditions in which any demand characteristics would be against making such errors. Thus although demand characteristics almost certainly play a role in producing eyewitness suggestibility effects, genuine memory-source confusions undoubtedly also occur.

We did not obtain a suggestibility effect among subjects tested with the source-monitoring test in the present experiments, but there is no reason to believe that such an effect could not be obtained with minor changes in the difficulty of the source-monitoring task. Although they are yet to be demonstrated in a standard suggestibility paradigm, there very likely are conditions under which misled subjects would be certain that a memory derived from the postevent information had been derived from the original event itself, and this certainty might survive the most stringent test.

The theoretical and empirical work presented in this paper has two implications for real-world testimony. First, our results, like those of McCloskey and Zaragoza (1985a), indicate that eyewitness memory may be less vulnerable to misleading suggestions than was once thought: In our task, at least, orienting subjects to attend to the sources of their memories eliminated the suggestibility effect (see also Zaragoza \& Koshmider, 1989). These results suggest that eyewitness testimony in natural situations might be improved by explicitly asking witnesses to identify the sources of their memories. Second, the source-monitoring hypothesis suggests that the likelihood that an eyewitness will confuse memories from various sources is determined by two general factors: (1) the degree of similarity between the target event and other sources of information, and (2) the stringency and appropriateness of the decisionmaking criteria employed during remembering. The present study constitutes a first step toward a new approach to eyewitness suggestibility effects. Characterizing the conditions under which misled subjects are (and are not) likely to make errors on a source-monitoring test would contribute substantially to our understanding of the processes that produce inaccurate remembering.

\section{REFERENCES}

Abra, J. C. (1972). List differentiation and forgetting. In C. P. Duncan, L. Sechrest, \& A. W. Melton (Eds.), Human memory: Festschrift for Benton J. Underwood (pp. 25-57). New York: Appleton-CenturyCrofts.

AlBA, J. W. (1984). Nature of inference representation. American Journal of Psychology, 97, 215-233. 
Atkinson, R. C., \& Juola, J. F. (1973). Factors influencing speed and accuracy of word recognition. In S. Kornblum (Ed.), Attention and performance $I V$ (pp. 583-612). New York: Academic Press.

BekERIAN, D. A., Bowers, J. M. (1983). Eyewitness testimony: Were we misled? Joumal of Experimental Psychology: Learning, Memory, \& Cognition, 9, 139-145.

Brown, E., Defrenbacher, K. \& Sturgill, W. (1977). Memory for faces and the circumstances of encounter. Journal of Applied Psychology, 62, 311-318.

Christianansen, R. E., \& OChalek, K. (1983). Editing misleading information from memory: Evidence for the coexistence of original and post-event information. Memory \& Cognition, 11, 467-475.

Crowder, R. G. (1976). Principles of learning and memory. Hillsdale, NJ: Erlbaum.

Fisher, R. P., \& Cuervo, A. (1983). Memory for physical features of discourse as a function of their relevance. Joumal of Experimental Psychology: Learning, Memory, \& Cognition, 9, 130-138.

Geiselman, R. E., \& Crawley, J. J. (1983). Incidental processing of speaker characteristics: Voice as connotative information. Joumal of Verbal Learning \& Verbal Behavior, 22, 15-23

Hasher, L., Griffin, M. (1978). Reconstructive and reproductive processes in memory. Joumal of Experimental Psychology: Human Learning \& Memory, 4, 318-330

Hashtroudi, S., Johnson, M. K., \& Chrosniak, L. (1989). Aging and source monitoring. Psychology \& Aging, 4, 106-112.

JACOBY, L. L., \& DALlas, M. (1981). On the relationship between autobiographical memory and perceptual leaming. Joumal of Experimental Psychology: General, 110, 306-340.

Johnson, M. K. (1988). Discriminating the origin of information. In T. F. Oltmanns \& B. A. Maher (Eds.), Delusional beliefs: Interdisciplinary perspectives. New York: Wiley.

Johnson, M. K., FoleY, M. A., \& LeACH, K. (1988). The consequences for memory of imagining in another person's voice. Memory \& Cognition, 16, 337-342.

Johnson, M. K., \& RAYE, C. L. (1981). Reality monitoring. Psychological Review, 88, 67-85.

Johnson, M. K., RAye, C. L., Wang, A. Y., \& TAYLoR, T. H. (1979). Fact and fantasy: The roles of accuracy and variability in confusing imaginations with perceptual experiences. Joumal of Experimental Psychology: Human Learning \& Memory, 5, 229-240.

LINDSAY, D. S. (1987). Whence comes this memory? Unpublished doctoral thesis. Princeton University, Princeton, NJ.

LindSAY, D. S., \& JoHNSON, M. K. (1989a). The reversed suggestibility effect. Bulletin of the Psychonomic Society, 27, 111-113.

LiNDSAY, D. S., \& JOHNSON, M. K. (1989b). Source monitoring Manuscript in preparation.

LofTUs, E. F. (1975). Leading questions and the eyewitness report Cognitive Psychology, 7, 560-572.

LofTus, E. F. (1979). Eyewitness testimony. Cambridge, MA: Wiley

LofTus, E. F. (1981). Mentalmorphosis: Alterations in memory produced by the mental bonding of new information to old. In $\mathbf{J}$. Long \& A. Baddeley (Eds.), Attention and performance IX (pp. 417-434). Hillsdale, NJ: Erlbaum.

LoFTus, E. F., \& LofTus, G. R. (1980). On the permanence of stored information in the human brain. American Psychologist, 35, 409-420.

Loftus, E. F., Miller, D. G., \& BurNs, H. J. (1978). Semantic integration of verbal information into a visual memory. Journal of $E x$ perimental Psychology: Human Learning \& Memory, 4, 19-31.

McCloskey, M., ZaragozA, M. (1985a). Misleading postevent information and memory for events: Arguments and evidence against memory impairment hypotheses. Journal of Experimental Psychology: General, 114, 1-16.

McCloskey, M., \& Zaragoza, M. (1985b). Postevent information and memory: Reply to Loftus, Schooler, and Wagenaar. Journal of Experimental Psychology: General, 114, 381-387.

MCGeoch, F. J. (1942). The psychology of human learning. New York: Longmans, Green.

Melton, A. W., \& IRWIN, J. M. (1940). The influence of degree of interpolated learning on retroactive inhibition and the overt transfer of specific responses. American Joumal of Psychology, 53, 173-203.
Morton, J., Hammersley, R. H., \& Bekerian, D. A. (1985). Headed records: A model for memory and its failures. Cognition, 20, 1-23.

Pirolli, P. L., \& Mitterer, J. O. (1984). The effect of leading questions on prior memory: Evidence for the coexistence of inconsistent traces. Canadian Journal of Psychology, 38, 135-141.

RAYE, C. L., Johnson, M. K. (1980). Reality monitoring vs. discriminating between external sources of memories. Bulletin of the Psychonomic Society, 15, 405-408.

RAYE, C. L., Johnson, M. K., TAYLoR, T. H. (1980). Is there something special about memory for internally generated information? Memory \& Cognition, 8, 141-148.

Shaughnessy, J. J., MAND, J. L. (1982). How permanent are memories of real-life events? American Joumal of Psychology, 95, $51-63$

TVERSKY, B., \& TUCHIN, M. (1989). A reconciliation of the evidence on eyewitness testimony: Comments on the Loftus-McCloskey \& Zaragoza debate. Joumal of Experimental Psychology: General, 118, 86-91

UNDERWOOD, B. J. (1945). The effect of successive interpolations on retroactive and proactive inhibition. Psychological Monographs, 59(Whole No. 273).

WAGENAAR, W. A. (1987, November). Evidence for parallel files in memory. Paper presented at the annual meeting of the Psychonomic Society, Seattle, WA.

WeLls, G. L., \& LofTUS, E. F. (Eds.). (1984). Eyewitness testimony: Psychological perspectives. New York: Cambridge University Press.

WINOGRAD, E. (1968). List differentiation as a function of frequency and retention interval. Journal of Experimental Psychology Monographs, 76, 1-18.

Zaragoza, M. S., Koshmider, J. W., III. (1989). Misled subjects may know more than their performance implies. Joumal of Experimental Psychology: Learning, Memory, \& Cognition, 15, 246-255.

\section{NOTES}

1. The tendency for control subjects to attribute more misleading-textonly than new items to the picture reflects an item-set effect. This item effect, which was also observed in Experiment 2, does not compromise our interpretation.

2. Ronald P. Fisher drew our attention to this interpretation of this interaction.

\section{APPENDIX \\ Narratives}

(Picture-and-text items are in italics and misleading-text-only items are shown in boldface. Brackets surround context material presented only in the misleading narrative, and braces surround context material presented only in the control narrative. The new items were clock, computer printout, Coke, gunbelt, handcuffs, handkerchief, man smoking, and typewriter. The picture-only items were blue sweater, coffee cup, desk nameplate, man with eyeglasses, mustache, pamphlets on desk, and pamphlets on shelves.)

"Crime Stoppers"' is an organization that offers monetary rewards for information concerning crimes. Although they are usually fairly small, Crime Stoppers offices are busy and intense places. Earlier, you were shown a picture of a Crime Stoppers office. The following is a description of that picture.

There are two men and two women in the room. The two men are seated, and both are holding telephone receivers. The two women are standing in the background to the right.

The man in the foreground is wearing a pinstripe suit with a solid burgundy tie [and a tie tack]. He is looking into the camera with a very stern look on his face, and is holding a telephone receiver in his left hand. He is seated in front of a desk 
that is cluttered with objects such as a telephone[,] \{and $\}$ a yellow writing pad [, and a pencil holder]. There is also a small stand-up desk calendar on the desk, as well as lots of papers and other things.

The man in the background (over to the left of the picture) is dressed in a grey suit. He has dark hair. He's sitting at a desk, talking on the telephone. There \{are [is a coat rack in the corner behind him and] some shelves on the wall directly behind him. These shelves run the length of the back wall. There is an open file folder [and a ruler] on the desk in front of him. The base of the telephone is also on the desk, but it is not in the picture. Standing a few yards to his left (that is, on the right side of the picture) are two women who appear to be engaged in conversation. The woman closer to the center of the picture is wearing a police uniform. Behind them, against the back wall, are the shelves. There \{are\} [is a coffee pot and] a number of door locks, door knobs, and various kinds of hinges on the shelvesprobably high-security locks and related gadgets. [The woman on the right side of the picture is holding a bunch of keys in her left hand.] The woman in uniform is holding some pamphlets in her right hand. [There is a police hat on one of the shelves above her head, although most of it isn't in the picture.] The women are standing almost directly behind the man in the foreground, who is sitting in a reddish-orange desk chair. There is a filing cabinet behind the woman on the right-near the righthand edge of the picture. The floor is grey carpet or tile. The ceiling is not pictured. Overall, the picture suggests a rather hectic atmosphere.

(Manuscript received April 6, 1988; revision accepted for publication September 13, 1988.)

\title{
Announcement
}

\author{
Conference on Flashbulb Memories and the Shuttle Explosion \\ Atlanta, Georgia \\ February 2-3, 1990
}

\section{Call for Papers}

On February 2-3, 1990, the Emory Cognition Project will host a working conference on "Flashbulb" Memories, with a special focus on memories of the 1986 explosion of the space shuttle Challenger. This conference will be jointly sponsored by the Office of Naval Research and the Air Force Office of Scientific Research.

We are especially interested in empirical studies of people's ability to recall how they first heard the news of this disaster. If you have data relevant to this issue, published or unpublished, please call or write: Eugene Winograd (404-727-7448) or Ulric Neisser (404-727-7973), Department of Psychology, Emory University, Atlanta, GA 30322. 